\title{
Genetic Polymorphisms of Nervous System Development and the Risk of Posttraumatic Stress Disorder
}

\author{
Diana Avetyan 1, Arsen Arakelyan 1,2, Gohar Mkrtchyan ${ }^{1 *}$ \\ ${ }^{1}$ Laboratory of Human Genomics and Immunomics, Institute of Molecular Biology, Armenian National Academy of Sciences, \\ Yerevan, Armenia \\ ${ }^{2}$ Group of Bioinformatics, Institute of Molecular Biology, Armenian National Academy of Sciences, Yerevan, Armenia \\ Email: *g_mkrtchyan@mb.sci.am
}

How to cite this paper: Avetyan, D., Arakelyan, A. and Mkrtchyan, G. (2018) Genetic Polymorphisms of Nervous System Development and the Risk of Posttraumatic Stress Disorder. American Journal of Molecular Biology, 8, 58-68.

https://doi.org/10.4236/ajmb.2018.81005

Received: November 18, 2017

Accepted: January 8, 2018

Published: January 11, 2018

Copyright $\odot 2018$ by authors and Scientific Research Publishing Inc. This work is licensed under the Creative Commons Attribution International License (CC BY 4.0).

http://creativecommons.org/licenses/by/4.0/

\begin{abstract}
Background: Posttraumatic stress disorder (PTSD) is a complex severe polygenic psychiatric disease, influenced by environmental and genetic factors. PTSD development and progression is characterized by cognitive impairment, which may result in altered processes of nervous system development and synaptic plasticity, where a number of growth factors and their receptors were shown to play important role. Since neurotrophins play an essential role in the development of central nervous system, it is widely implicated in psychiatric disorders. The aim of this study is to investigate the potential association functional polymorphisms of genes encoding netrin G1 (NTNG1), brain-derived neurotrophic factor (BDNF), nerve growth factor (NGF) and its receptor (NGFR) with PTSD. Methods: Study groups consisted of 200 combat veterans with PTSD and an equal number of controls with no family or past history of any psychiatric disorders. The DNA samples were genotyped for NTNG1 rs62811; BDNF rs6265; NGF rs6330, rs4839435; NGFR rs11466155, rs734194 SNPs using polymerase chain reaction with sequence specific primers. Results: According to the results, NGF rs6330 was overrepresented in patients with PTSD compared to controls. Furthermore, negative association for BDNF rs6265, NGF rs4839435 and NGFR rs734194 was observed in PTSD patients. Conclusions: In summary, BDNF rs6265, NGF rs6330, rs4839435 and NGFR rs734194 are implicated in PTSD in Armenian population. However, further research is required to provide the definitive evidence of selected polymorphism association with gene expression.
\end{abstract}

\section{Keywords}

BDNF, NGF, NGFR, NTNG1, Posttraumatic Stress Disorder 


\section{Introduction}

Posttraumatic stress disorder (PTSD) is a complex severe multifactorial polygenic psychiatric disease (ICD-10 code: 43.1; DSM-V code: 309.81 ), influenced by environmental and genetic factors [1] [2]. Although most people experience a traumatic event during their lives and many of them experience multiple traumatic events, only a minority will develop PTSD [3] [4], suggesting that individual vulnerability and resilience factors are important in PTSD pathophysiology. PTSD is heritable [5] [6] [7] [8], suggesting that these individual differences might, in part, be explained by genetic factors. However, our understanding of biological mechanisms underlying PTSD is still incomplete. The results of many studies show that genes related to the physiological stress response (e.g., glucocorticoid receptor activity, neuroendocrine release) [9] [10] [11], learning and memory (e.g., plasticity) [12] [13], mood, and pain perception are tied to neural endophenotype associated with PTSD. These genes are associated with and can predict the structure and the function of neurons in brain areas responsible for such functions, as attention, decision-making, memory, cognition, response to the pain and other threats. Evidence suggests these risk polymorphisms and neural intermediate phenotypes are vulnerabilities toward developing PTSD in the aftermath of trauma, or vulnerabilities toward particular symptoms once PTSD has developed [14] [15].

PTSD development and progression is characterized by cognitive impairment, which may result in altered processes of nervous system development and synaptic plasticity [16], where a number of growth factors and their receptors were shown to play important role.

Netrins including netrin G1 (NTNG1) are known to be axon guidance factors in the developing brain. They could be very important contributors to the genetic risk for psychosis [17]. Neurotrophin family is another important class of signaling molecules in the brain recognized for their nerve growth promoting function and is recently identified as crucial factors in regulating neuronal activity in the central and peripheral nervous systems. The family members including nerve growth factor (NGF) and brain-derived neurotrophic factor (BDNF) are the essential mediators of synaptic and morphological plasticity, neuronal growth, survival, and differentiation, especially in the developing brain. It is thought they may play an important role in pathogenesis of PTSD. We examined the hypothesis that allelic variations in NTNG1, NGF, NGFR, as well as BDNF contribute to the risk of development of PTSD.

\section{Materials and Methods}

\subsection{Study Subjects}

Study groups consisted of 200 combat veterans with PTSD (mean age: $\mathrm{M} \pm \mathrm{SD}=$ $54.52 \pm 11.0$ years) and an equal number of controls (mean age: $\mathrm{M} \pm \mathrm{SD}=43.6 \pm$ 9.1 years) with no family or past history of any mental disorders, as well as disorders characterized by alterations in apoptosis and synaptic plasticity. Clinical 
diagnosis was made according to DSM-IV-TR (American Psychiatric Association) criteria [18]. The study was verified and approved by the Ethics Committee of the Institute of Molecular Biology (IRB \#00004079). The informed consents from all study subjects were collected for these studies.

\subsection{Blood Sampling and Genomic DNA Extraction}

The experiments were performed using genomic DNA samples of study subjects. Genomic DNA was prepared from peripheral venous blood using standard phenol-chloroform extraction [19] and stored at $-30^{\circ} \mathrm{C}$ until use.

\subsection{Primer Design}

DNA samples were genotyped for NTNG1 rs62811; BDNF rs6265; NGF rs6330, rs4839435; NGFR rs11466155, rs734194 functional SNPs (Table 1). The SNPs were selected based on either their functionality according to the National Center of Biotechnology Information (NCBI) databases (http://www.ncbi.nlm.nih.gov/), tagging results obtained using the International HapMap Project database (http://hapmap.ncbi.nlm.nih.gov) and literature review (see the Results section).

All primers for PCR-SSP were designed using the genomic sequences in the GenBank nucleotide sequence database (https://www.ncbi.nlm.nih.gov/genbank/) and are indicated. The primers sequences were as follows:

- NTNG1 rs628117: 5'-ATCCTTGGAATGAAAGCCCA for standard allele; 5'-ATCCTTGGAATGAAAGCCCG for minor allele; 5'-TCACTGCCCTCT GTGTGCAGTG constant, product length $233 \mathrm{bp}$;

- BDNF rs6265: 5'-GGCTGACACTTTCGAACACG for standard allele; 5'GGCTGACACTTTCGAACACA for minor allele; 5'- GTTACCCACTCA CTAATACTG constant, product length $271 \mathrm{bp}$;

- NGF rs6330: 5'-GACACACCATCCCCCAAGC for standard allele; 5'-GAC ACACCATCCCCCAAGT for minor allele; 5'-AGGCTGGGTGCTAAAC AGC constant, product length $194 \mathrm{bp}$;

- NGF rs4839435: 5'-TGGGTGCCAAAAAGCTTGGC for standard allele; 5'-TGGGTGCCAAAAAGCTTGGT for minor allele; 5'-GCAGCTCCTGC

Table 1. Brief characteristics of selected genes and SNPs.

\begin{tabular}{cccccc}
\hline \multicolumn{2}{c}{ Gene } & & \multicolumn{3}{c}{ SNP } \\
\hline Name & Location & NCBI RefSeq & ID & Substitution $^{\text {a }}$ & Location (type) \\
\hline NTNG1 & 1p13.3 & NG_042821.1 & rs628117 & A > G & Intronic \\
BDNF & 11 p13 & NG_011794.1 & rs6265 & G > A & exonic (missense) \\
NGF & 1p13.1 & NG_007944.1 & rs6330 & G > A & exonic (missense) \\
& & & rs4839435 & G > A & Intronic \\
NGFR & 17q21-q22 & NM_002507.3 & rs11466155 & C > T & exonic (synonymous) \\
& & & rs734194 & T > G & 3'-UTR
\end{tabular}

a. On forward strand. 
AATTATCCA constant, product length $188 \mathrm{bp}$;

- NGFR rs11466155: 5'-AGGCTATGTAGGCCACAAGG for standard allele; 5'AGGCTATGTAGGCCACAAGA for minor allele; 5'-CAGAGGGCTCGG ACAGCACA constant, product length $210 \mathrm{bp}$;

- NGFR rs734194: 5’-GCTGGAGCTGGCGTCTGTCT for standard allele; 5'-GCTGGAGCTGGCGTCTGTCG for minor allele; 5'-CTAGAGCTGGGA GAAATCCC constant, product length $186 \mathrm{bp}$.

\subsection{Polymerase Chain Reaction with Sequence Specific Primers}

Genotyping was carried out by polymerase chain reaction with sequence-specific primers (PCR-SSP) according to protocol developed in Bunce et al. [20]. Final reaction volume contained $0.3 \mu$ l allele specific primers, the same amount of constant primers (100 pM), $0.3 \mu$ control primers (100 pM in 11$), 5 \mu l 0.01 \mathrm{M}$ Tris-HCl buffer ( $\mathrm{pH}$ 8.5), $0.14 \mu \mathrm{l} 0.02 \mathrm{M}$ dNTPs, $0.5 \mu$ l genome DNA samples, $1.1 \mu \mathrm{l} 0.025 \mathrm{MgCl}_{2}, 1.37 \mu \mathrm{l} 0.67 \mathrm{M}$ Tris- $\mathrm{HCl}$ buffer ( $\mathrm{pH} 8.8$ ) containing $0.166 \mathrm{M}$ $\left(\mathrm{NH}_{4}\right)_{2} \mathrm{SO}_{4}$, and $1 \%$ Tween $20,0.07 \mu \mathrm{l}$ Taq polymerase (1 unit/ml) and $5.68 \mu \mathrm{l}$ water. PCR cycles and conditions used are presented in Table 2.

The presence/absence of allele-specific amplicons in the PCR products was visualized in $2 \%$ agarose gel stained with ethidium bromide fluorescent dye using DNA molecular weight markers as a reference. To check the reproducibility of results, randomly selected DNA samples (10\% of total) were genotyped twice.

\subsection{Data Analysis}

The distributions of genotypes for selected SNPs were checked for correspondence to Hardy-Weinberg equilibrium. The significance of differences in genotype and allele frequencies and minor allele carriage between patients and healthy subjects was determined using Pearson's Chi-square test. P-values $<0.05$ were considered statistically significant. P-values adjusted by Bonferroni multiple

Table 2. The PCR conditions.

\begin{tabular}{cccc}
\hline Number of cycles & Step & Temperature, ${ }^{\circ} \mathrm{C}$ & Duration \\
\hline Cycle 1: $(1 \times)$ & Step 1 & 96.0 & $1 \mathrm{~min}$ \\
& Step 1 & 96.0 & $20 \mathrm{sec}$ \\
Cycle 2: $(5 \times)$ & Step 2 & 70.0 & $45 \mathrm{sec}$ \\
& Step 3 & 72.0 & $25 \mathrm{sec}$ \\
& Step 1 & 96.0 & $25 \mathrm{sec}$ \\
Cycle 3: $(21 \times)$ & Step 2 & 65.0 & $50 \mathrm{sec}$ \\
& Step 3 & 72.0 & $30 \mathrm{sec}$ \\
& Step 1 & 96.0 & $30 \mathrm{sec}$ \\
Cycle 4: $(4 \times)$ & Step 2 & 55.0 & $1 \mathrm{~min}$ \\
& Step 3 & 72.0 & $1 \mathrm{~min} \mathrm{30} \mathrm{sec}$ \\
\hline
\end{tabular}


comparison correction are further indicated as $\mathrm{p}_{\text {corrected }}$, and those not adjusted as $\mathrm{p}_{\text {nominal }}$. All calculations were performed using SPSS 21 (SPSS Inc, USA) software.

\section{Results}

Cases and controls were well matched in terms of gender and ethnicity. Genotype frequencies did not deviate from HWE. The results of genotyping are presented in Table 3.

Table 3. Distribution of genotypes, alleles and minor allele carriage frequencies of the selected SNPs in patients with PTSD and controls.

\begin{tabular}{|c|c|c|c|c|c|c|}
\hline \multirow{2}{*}{$\begin{array}{c}\text { Gene (SNP) } \\
\text { NTNG1 rs628117 }\end{array}$} & \multicolumn{3}{|c|}{ Genotypes } & \multicolumn{2}{|c|}{ Alleles } & \multirow{2}{*}{$\begin{array}{c}\text { Carriage } \\
\text { G }\end{array}$} \\
\hline & AA & AG & GG & A & G & \\
\hline PTSD & $47(0.36)$ & $66(0.5)$ & $19(0.14)$ & $160(0.6)$ & $104(0.4)$ & $85(0.64)$ \\
\hline Controls & $36(0.34)$ & $43(0.41)$ & $26(0.25)$ & $115(0.55)$ & $95(0.45)$ & $69(0.66)$ \\
\hline $\mathrm{P}$ & & & & \multicolumn{2}{|c|}{$0.2^{\mathrm{a}}$} & $0.8^{\mathrm{b}}$ \\
\hline OR $(95 \% \mathrm{CI})$ & & & & \multicolumn{2}{|c|}{$0.79(0.55-1.14)$} & $1.06(0.62-1.82)$ \\
\hline BDNF rs6265 & GG & GA & AA & G & A & A \\
\hline PTSD & $150(0.75)$ & $48(0.24)$ & $2(0.01)$ & $348(0.87)$ & $52(0.13)$ & $50(0.25)$ \\
\hline Controls & $129(0.645)$ & $67(0.335)$ & $4(0.02)$ & $325(0.81)$ & $75(0.19)$ & $71(0.36)$ \\
\hline $\mathrm{P}$ & & & & \multicolumn{2}{|c|}{$0.026^{\mathrm{a}}$} & $0.02^{\mathrm{b}}$ \\
\hline OR (95\% CI) & & & & \multicolumn{2}{|c|}{$0.65(0.44-0.95)$} & $1.65(1.07-2.54)$ \\
\hline NGF rs6330 & $\mathrm{CC}$ & CT & TT & $\mathrm{C}$ & $\mathrm{T}$ & $\mathrm{T}$ \\
\hline PTSD & $66(0.33)$ & $106(0.53)$ & $28(0.14)$ & $238(0.6)$ & $162(0.4)$ & $134(0.67)$ \\
\hline Controls & $130(0.65)$ & $58(0.29)$ & $12(0.06)$ & $318(0.8)$ & $82(0.2)$ & $70(0.35)$ \\
\hline $\mathrm{P}$ & & & & \multicolumn{2}{|c|}{$2.04 \mathrm{E}-09^{\mathrm{a}}$} & $4.20 \mathrm{E}-10^{\mathrm{b}}$ \\
\hline OR $(95 \% \mathrm{CI})$ & & & & \multicolumn{2}{|c|}{$2.64(1.93-3.61)$} & $3.77(2.49-5.7)$ \\
\hline NGF rs4839435 & GG & GA & AA & G & A & A \\
\hline PTSD & $130(0.65)$ & $66(0.33)$ & $4(0.02)$ & $326(0.8)$ & $74(0.2)$ & $70(0.35)$ \\
\hline Controls & $85(0.425)$ & $97(0.485)$ & $18(0.09)$ & $267(0.67)$ & $133(0.33)$ & $115(0.58)$ \\
\hline $\mathrm{P}$ & & & & \multicolumn{2}{|c|}{$4.00 \mathrm{E}-06^{\mathrm{a}}$} & $1.20 \mathrm{E}-05^{\mathrm{b}}$ \\
\hline OR (95\% CI) & & & & \multicolumn{2}{|c|}{$0.46(0.33-0.63)$} & $0.4(0.27-0.6)$ \\
\hline $\begin{array}{c}\text { NGFR } \\
\text { rs11466155 }\end{array}$ & $\mathrm{CC}$ & $\mathrm{CT}$ & $\mathrm{TT}$ & $\mathrm{C}$ & $\mathrm{T}$ & $\mathrm{T}$ \\
\hline PTSD & $109(0.545)$ & $82(0.41)$ & $9(0.045)$ & $300(0.75)$ & $100(0.25)$ & $91(0.46)$ \\
\hline Controls & $110(0.55)$ & $75(0.375)$ & $15(0.075)$ & $295(0.74)$ & $105(0.26)$ & $90(0.45)$ \\
\hline $\mathrm{p}$ & & & & \multicolumn{2}{|c|}{$1.37^{\mathrm{a}}$} & $2^{\mathrm{b}}$ \\
\hline OR (95\% CI) & & & & \multicolumn{2}{|c|}{$0.94(0.68-1.29)$} & $0.98(0.66-1.45)$ \\
\hline NGFR rs734194 & $\mathrm{TT}$ & TG & GG & $\mathrm{T}$ & G & G \\
\hline PTSD & $164(0.82)$ & $34(0.17)$ & $2(0.01)$ & $362(0.9)$ & $38(0.1)$ & $36(0.18)$ \\
\hline Controls & $109(0.545)$ & $74(0.37)$ & $17(0.085)$ & $292(0.73)$ & $108(0.27)$ & $91(0.46)$ \\
\hline $\mathrm{p}$ & & & & \multicolumn{2}{|c|}{$2.74 \mathrm{E}-10^{\mathrm{a}}$} & $8.82 \mathrm{E}-09^{\mathrm{b}}$ \\
\hline OR (95\% CI) & & & & \multicolumn{2}{|c|}{$0.28(0.19-0.42)$} & $0.26(0.17-0.42)$ \\
\hline
\end{tabular}

a. $\mathrm{p}_{\text {corrected }}$ values for comparison of mutant allele frequency between PTSD patients and controls. b. $\mathrm{p}_{\text {corrected }}$ values for comparison of mutant allele carriage between PTSD patients and controls. 
According to the results obtained, for NTNG1 rs628117 no significant differences in the allele and genotype frequency were found between PTSD patients and controls. In the case of the BDNF gene the rs6265* A allele was lower in patients than in controls $\left(0.13\right.$ vs. $0.19, \mathrm{p}_{\text {nominal }}=0.026, \mathrm{OR}=0.65,95 \% \mathrm{CI}: 0.44$ 0.95). Also, the number of rs $6265 * A$ minor allele carriers was lower in the group of patients compared to controls ( 0.25 vs. $0.36, \mathrm{p}_{\text {nominal }}=0.02, \mathrm{OR}=1.65$, $95 \% \mathrm{CI}: 1.07-2.54)$. Further, we found that the rs $6330 * \mathrm{~T}$ allele of the NGF gene was overrepresented in patients with PTSD compared to controls (0.4 vs. 0.2, $\left.\mathrm{p}_{\text {nominal }}=1.02 \mathrm{E}-9, \mathrm{OR}=2.64,95 \% \mathrm{CI}: 1.93-3.61\right)$. Also, the carriers of the rs6330 * T minor allele $(\mathrm{CT}+\mathrm{TT})$ were more frequent in patients than in controls $(0.67$ vs. $\left.0.35, \mathrm{p}_{\text {nominal }}=2.1 \mathrm{E}-10, \mathrm{OR}=3.77,95 \% \mathrm{CI}: 2.49-5.7\right)$.

On the contrary, the frequency ( 0.2 vs. $0.33, \mathrm{p}_{\text {nominal }}=2.0 \mathrm{E}-6, \mathrm{OR}=0.46$, $95 \% \mathrm{CI}: 0.33-0.63)$ and carriers $\left(0.35\right.$ vs. $0.58, \mathrm{p}_{\text {nominal }}=6.0 \mathrm{E}-6, \mathrm{OR}=0.4$, $95 \%$ CI: 0.27 - 0.6) of the rs 4839435 * A minor allele of the NGF gene were lower in PTSD patients than in controls. The NGFR rs734194 * T minor allele frequency again was lower in patients than in controls ( 0.1 vs. $0.27, \mathrm{p}_{\text {nominal }}=1.37 \mathrm{E}-10, \mathrm{OR}=$ $0.28,95 \%$ CI: $0.19-0.42)$. The same applies to the carriers of the NGFR rs734194 $* \mathrm{~T}$ allele $\left(0.18\right.$ vs. $0.46, \mathrm{p}_{\text {nominal }}=4.41 \mathrm{E}-9, \mathrm{OR}=0.26,95 \% \mathrm{CI}$ : $\left.0.17-0.42\right)$. After Bonferroni correction, difference in allele frequency between the patient and control groups for these minor alleles remained significant.

\section{Discussion}

The etiology and pathology of PTSD is not fully understood. Neurobiological abnormalities in PTSD patients are numerous and probably occur as a result of dysregulation of several stress-mediating systems when exposed to psychological trauma. In certain extreme conditions, people with genetic predispositions have higher probability of developing these pathologic changes.

Many observations suggest that PTSD is due to a series of genetic anomalies in neural development and differentiation [10] [21] [22]. Neurotrophins NGF and BDNF, which are known for their classical role in neurogenesis and synaptic plasticity, are most probably involved in trauma memory and cognitive dysfunction in PTSD.

The present study investigates the BDNF val66met (rs6265), the NTNG1 rs628117, the NGF rs6330 and rs4839435, and the NGFR rs11466155 and rs734194 variants and the risk of development of PTSD in combat veterans in Armenian population

BDNF is part of the neurotrophin family of growth factors, such as the NGF, neurotrophins 3 and 4 (NT-3, NT-4). They are responsible for enhancing progenitor-cell proliferation and differentiation, cell growth, regeneration processes, neuronal survival, synaptic regulation and remodeling, the regulation of plasticity, and repair and connectivity in the brain [23]. Investigations of biological factors commonly associated with learning and memory formation have indicated that BDNF may be a promising candidate. BDNF is highly expressed in the mamma- 
lian brain, especially in the hippocampus, which is functionally associated with learning and memory processes [24] [25]. Its binding to TrkB (tyrosine receptor kinase) causes intracellular cascades affecting neuronal development, plasticity, long-term potentiation, and apoptosis [26] [27]. The polymorphism rs6265, also known as Val66Met, which results in a change from valine to methionine in the precursor protein, of BDNF has been hypothesised to be important in fear learning and has shown some promising associations in animal models [28]. There are several studies with controversial results of BDNF rs6265 in association with PTSD susceptibility [25] [29]. Our study showed the involvement of BDNF rs6265 in PTSD. It shows a potential protective factor of the minor allele carriers for PTSD. However further research is required to provide the definitive evidence of BDNF rs6265 polymorphism association with BDNF level.

Netrins including NTNG1 are known to be axon guidance factors in the developing brain. They could be very important contributors to the genetic risk for psychosis. Moreover, studies suggested that NTNG1 genetic polymorphisms probably are implicated in pathogenesis of schizophrenia [30] [31] [32], ischemic stroke as well as other neurodevelopment disorders [33]. In our study, the NTNG1 rs628117 genotypes were equally distributed in the groups of PTSD patients and controls, so it is not associated with PTSD in Armenian population.

Nerve growth factor is important for the development and maintenance of the sympathetic and sensory nervous systems. Extracellular ligand for the NTRK1 and NGFR receptors activates cellular signalling cascades through corresponding receptor tyrosine kinase cascade to regulate neuronal proliferation, differentiation and survival [34]. In the literature, there are a limited number of studies evaluating the relationship between NGF gene and PTSD. However, there are several studies show association between NGF and anxiety and psychiatric disorders [35] [36] [37] [38]. A non-synonymous single-nucleotide polymorphism in the NGF gene, rs6330, produces an alanine to valine replacement at amino acid position [36], and is thought to involve intracellular processing and secretion of NGF. Allelic variations at the rs6330 locus have previously shown associations with anxiety-related traits and affective disorders [37] [38] [39].

These neurotrophins exert their actions through binding to the NGFR that belongs to the tumor necrosis factor receptor super family and has similar affinity for all neurotrophins as well as to members of neurotrophic tyrosine receptor kinase family, each selectively binding a different neurotrophin [40] [41] [42].

The results of the present study demonstrated a positive association between PTSD and the rs6330 SNP of the NGF gene. Also, a negative association between this disorder and rs4839435 SNP of the NGF gene as well as the rs734194 SNP of the NGFR gene was found.

\section{Conclusion}

In summary, our results demonstrate the association of BDNF rs6265, NGF rs6330, rs4839435, and NGFR rs734194 functional SNPs with PTSD in Arme- 
nian population. However, further research is required to provide the definitive evidence of selected polymorphism association with gene expression.

\section{Acknowledgements}

The authors express their gratitude to the administration and medical staff of the Stress Center of the ArtMed Medical Rehabilitation Center of the Republic of Armenia, Artsakh Scientific Center of the Republic of Artsakh and Erebouni Medical Center MH RA for selection of PTSD patients and healthy control subjects for this study.

This work made possible in part by a research grant from the Armenian National Science and Education Fund (ANSEF) based in New York, USA.

\section{References}

[1] American Psychiatric Association. (2013) Diagnostic and Statistical Manual of Mental Disorders.

[2] World Health Organisation. (2016) ICD-10 Version: 2016. Who. https://doi.org/10.1177/1071100715600286

[3] Kessler, R.C., Sonnega, A., Bromet, E., Hughes, M. and Nelson, C.B. (1995) Posttraumatic Stress Disorder in the National Comorbidity Survey. Archives of General Psychiatry, 52, 1048-1060. http://www.ncbi.nlm.nih.gov/pubmed/7492257 https://doi.org/10.1001/archpsyc.1995.03950240066012

[4] Kessler, R.C., Berglund, P., Demler, O., Jin, R., Merikangas, K.R. and Walters, E.E. (2005) Lifetime Prevalence and Age-of-Onset Distributions of DSM-IV Disorders in the National Comorbidity Survey Replication. Archives of General Psychiatry, 62, 593. https://doi.org/10.1001/archpsyc.62.6.593

[5] Afifi, T.O., Asmundson, G.J.G., Taylor, S. and Jang, K.L. (2010) The Role of Genes and Environment on Trauma Exposure and Posttraumatic Stress Disorder Symptoms: A Review of Twin Studies. Clinical Psychology Review, 30, 101-112. https://doi.org/10.1016/j.cpr.2009.10.002

[6] Koenen, K.C., Duncan, L.E., Liberzon, I. and Ressler, K.J. (2013) From Candidate Genes to Genome-Wide Association: The Challenges and Promise of Posttraumatic Stress Disorder Genetic Studies. Biological Psychiatry, 74, 634-636. https://doi.org/10.1016/j.biopsych.2013.08.022

[7] Almli, L.M., Fani, N., Smith, A.K. and Ressler, K.J. (2014) Genetic Approaches to Understanding Post-Traumatic Stress Disorder. International Journal of Neuropsychopharmacology, 17, 355-370. https://doi.org/10.1017/S1461145713001090

[8] Lebois, L.A.M., Wolff, J.D. and Ressler, K.J. (2016) Neuroimaging Genetic Approaches to Posttraumatic Stress Disorder. Experimental Neurology, 284, 141-152. https://doi.org/10.1016/j.expneurol.2016.04.019

[9] Zannas, A.S., Wiechmann, T., Gassen, N.C. and Binder, E.B. (2016) Gene-StressEpigenetic Regulation of FKBP5: Clinical and Translational Implications. Neuropsychopharmacology, 41, 261-274. https://doi.org/10.1038/npp.2015.235

[10] Li, S., Papale, L.A., Zhang, Q., Madrid, A., Chen, L., Chopra, P., Keleş, S., Jin, P. and Alisch, R.S. (2016) Genome-Wide Alterations in Hippocampal 5-Hydroxymethylcytosine Links Plasticity Genes to Acute Stress. Neurobiology of Disease, 86, 99-108. https://doi.org/10.1016/j.nbd.2015.11.010

[11] Binder, E.B., Bradley, R.G., Liu, W., Epstein, M.P., Deveau, T.C., Mercer, K.B., 
Tang, Y., Gillespie, C.F., Heim, C.M., Nemeroff, C.B., Schwartz, A.C., Cubells, J.F. and Ressler, K.J. (2008) Association of FKBP5 Polymorphisms and Childhood Abuse with Risk of Posttraumatic Stress Disorder Symptoms in Adults. JAMA, 299, 1291-305. https://doi.org/10.1001/jama.299.11.1291

[12] Lee, J.H. and Kim, J.H. (2016) Dopamine-Dependent Synaptic Plasticity in an Amygdala Inhibitory Circuit Controls Fear Memory Expression. BMB Reports, 49, 1-2. http://www.ncbi.nlm.nih.gov/pubmed/26674344 https://doi.org/10.5483/BMBRep.2016.49.1.258

[13] Flor, H. and Nees, F. (2014) Learning, Memory and Brain Plasticity in Posttraumatic Stress Disorder: Context Matters. Restorative Neurology and Neuroscience, 32, 95-102.

[14] Admon, R., Milad, M.R. and Hendler, T. (2013) A Causal Model of Post-Traumatic Stress Disorder: Disentangling Predisposed from Acquired Neural Abnormalities. Trends in Cognitive Sciences, 17, 337-347. https://doi.org/10.1016/j.tics.2013.05.005

[15] Meyer-Lindenberg, A. and Weinberger, D.R. (2006) Intermediate Phenotypes and Genetic Mechanisms of Psychiatric Disorders. Nature Reviews Neuroscience, 7, 818-827. https://doi.org/10.1038/nrn1993

[16] Seal, K.H., Bertenthal, D., Samuelson, K., Maguen, S., Kumar, S. and Vasterling, J.J. (2016) Association between Mild Traumatic Brain Injury and Mental Health Problems and Self-Reported Cognitive Dysfunction in Iraq and Afghanistan Veterans. Journal of Rehabilitation Research \& Development, 53, 185-198. https://doi.org/10.1682/JRRD.2014.12.0301

[17] Wilcox, J.A. and Quadri, S. (2014) Replication of NTNG1 Association in Schizophrenia. Psychiatric Genetics, 24, 266-268. https://doi.org/10.1097/YPG.0000000000000061

[18] APA (2000) Diagnostic and Statistical Manual of Mental Disorders. 4th Edition, Text Revision.

[19] Sambrook, J. and Russell, D.W. (2001) Molecular Cloning: A Laboratory Manual. Cold Spring Harbor Laboratory Press, Cold Spring Harbor. https://books.google.cz/books/about/Molecular_Cloning.html?id=Bosc5JVxNpkC\& redir_esc $=\mathrm{y}$

[20] Bunce, M., O’Neill, C.M., Barnardo, M.C., Krausa, P., Browning, M.J., Morris, P.J. and Welsh, K.I. (1995) Phototyping: Comprehensive DNA Typing for HLA-A, B, C, DRB1, DRB3, DRB4, DRB5 \& DQB1 by PCR with 144 Primer Mixes Utilizing Sequence-Specific Primers (PCR-SSP). Tissue Antigens, 46, 355-367.

http://www.ncbi.nlm.nih.gov/pubmed/8838344 https://doi.org/10.1111/j.1399-0039.1995.tb03127.x

[21] Wingo, A.P., Almli, L.M., Stevens, J.J., Klengel, T., Uddin, M., Li, Y., Bustamante, A.C., Lori, A., Koen, N., Stein, D.J., Smith, A.K., Aiello, A.E., Koenen, K.C., Wildman, D.E., Galea, S., Bradley, B., Binder, E.B., Jin, P., Gibson, G., Ressler, K.J. and Ressler, K.J. (2015) DICER1 and microRNA Regulation in Post-Traumatic Stress Disorder with Comorbid Depression. Nature Communications, 6, 10106. https://doi.org/10.1038/ncomms10106

[22] Boyajyan, A., Avetyan, D., Hovhannisyan, L. and Mkrtchyan, G. (2015) Genetics of Posttraumatic Stress Disorder: Candidate Genes and Their Implication in the Disease-Associated Molecular Pathomechanisms. In: Durbano, F., Ed., A Fresh Look at Anxiety Disorders, InTech, EU, 65-88. https://doi.org/10.5772/60443

[23] Kotlęga, D., Peda, B., Zembroń-Łacny, A., Gołąb-Janowska, M. and Nowacki, P. (2017) The Role of Brain-Derived Neurotrophic Factor and Its Single Nucleotide 
Polymorphisms in Stroke Patients. Neurologia $i$ Neurochirurgia Polska, 51, 240-246. https://doi.org/10.1016/j.pjnns.2017.02.008

[24] Yamada, K. and Nabeshima, T. (2003) Brain-Derived Neurotrophic Factor/TrkB Signaling in Memory Processes. Journal of Pharmacological Sciences, 91, 267-270. http://www.ncbi.nlm.nih.gov/pubmed/12719654 https://doi.org/10.1254/jphs.91.267

[25] Bruenig, D., Lurie, J., Morris, C.P., Harvey, W., Lawford, B., Young, R.M. and Voisey, J. (2016) A Case-Control Study and Meta-Analysis Reveal BDNF Val66Met Is a Possible Risk Factor for PTSD. Neural Plasticity, 2016, Article ID: 6979435.

[26] Monteggia, L.M., Barrot, M., Powell, C.M., Berton, O., Galanis, V., Gemelli, T., Meuth, S., Nagy, A., Greene, R.W. and Nestler, E.J. (2004) Essential Role of Brain-Derived Neurotrophic Factor in Adult Hippocampal Function. Proceedings of the National Academy of Sciences, 101, 10827-10832. https://doi.org/10.1073/pnas.0402141101

[27] Tapia-Arancibia, L., Rage, F., Givalois, L. and Arancibia, S. (2004) Physiology of BDNF: Focus on Hypothalamic Function. Frontiers in Neuroendocrinology, 25, 77-107. https://doi.org/10.1016/j.yfrne.2004.04.001

[28] Andero, R., Choi, D.C. and Ressler, K.J. (2014) BDNF-TrkB Receptor Regulation of Distributed Adult Neural Plasticity, Memory Formation, and Psychiatric Disorders. Progress in Molecular Biology and Translational Science, 122, 169-192. https://doi.org/10.1016/B978-0-12-420170-5.00006-4

[29] Valente, N.L.M., Vallada, H., Cordeiro, Q., Miguita, K., Bressan, R.A., Andreoli, S.B., Mari, J.J. and Mello, M.F. (2011) Candidate-Gene Approach in Posttraumatic Stress Disorder after Urban Violence: Association Analysis of the Genes Encoding Serotonin Transporter, Dopamine Transporter, and BDNF. Journal of Molecular Neuroscience, 44, 59-67. https://doi.org/10.1007/s12031-011-9513-7

[30] Aoki-Suzuki, M., Yamada, K., Meerabux, J., Iwayama-Shigeno, Y., Ohba, H., Iwamoto, K., Takao, H., Toyota, T., Suto, Y., Nakatani, N., Dean, B., Nishimura, S., Seki, K., Kato, T., Itohara, S., Nishikawa, T. and Yoshikawa, T. (2005) A Family-Based Association Study and Gene Expression Analyses of Netrin-G1 and -G2 Genes in Schizophrenia. Biological Psychiatry, 57, 382-393.

https://doi.org/10.1016/j.biopsych.2004.11.022

[31] Ohtsuki, T., Horiuchi, Y., Koga, M., Ishiguro, H., Inada, T., Iwata, N., Ozaki, N., Ujike, H., Watanabe, Y., Someya, T. and Arinami, T. (2008) Association of Polymorphisms in the Haplotype Block Spanning the Alternatively Spliced Exons of the NTNG1 Gene at 1p13.3 with Schizophrenia in Japanese Populations. Neuroscience Letters, 435, 194-197. https://doi.org/10.1016/j.neulet.2008.02.053

[32] Zhu, Y., Yang, H., Bi, Y., Zhang, Y., Zhen, C., Xie, S., Qin, H., He, J., Liu, L. and Liu, Y. (2011) Positive Association between NTNG1 and Schizophrenia in Chinese Han Population. Journal of Genetics, 90, 499-502. https://doi.org/10.1007/s12041-011-0112-8

[33] Stepanyan, A., Zakharyan, R. and Boyajyan, A. (2013) The Netrin G1 Gene rs628117 Polymorphism Is Associated with Ischemic Stroke. Neuroscience Letters, 549, 74-77. https://doi.org/10.1016/j.neulet.2013.05.066

[34] Szczepankiewicz, A., Rachel, M., Sobkowiak, P., Kycler, Z., Wojsyk-Banaszak, I., Schöneich, N., Szczawińska-Popłonyk, A. and Bręborowicz, A. (2013) Neurotrophin Serum Concentrations and Polymorphisms of Neurotrophins and Their Receptors in Children with Asthma. Respiratory Medicine, 107, 30-36. https://doi.org/10.1016/j.rmed.2012.09.024 
[35] Castren, E., Voikar, V. and Rantamaki, T. (2007) Role of Neurotrophic Factors in Depression. Current Opinion in Pharmacology, 7, 18-21. https://doi.org/10.1016/j.coph.2006.08.009

[36] Syed, Z., Dudbridge, F. and Kent, L. (2007) An Investigation of the Neurotrophic Factor Genes GDNF, NGF, and NT3 in Susceptibility to ADHD. American Journal of Medical Genetics Part B: Neuropsychiatric Genetics, 144B, 375-378. https://doi.org/10.1002/ajmg.b.30459

[37] Lester, K.J., Hudson, J.L., Tropeano, M., Creswell, C., Collier, D.A., Farmer, A., Lyneham, H.J., Rapee, R.M. and Eley, T.C. (2012) Neurotrophic Gene Polymorphisms and Response to Psychological Therapy. Translational Psychiatry, 2, e108. https://doi.org/10.1038/tp.2012.33

[38] Zakharyan, R., Atshemyan, S., Gevorgyan, A. and Boyajyan, A. (2014) Nerve Growth Factor and Its Receptor in Schizophrenia. BBA Clinical, 1, 24-29. https://doi.org/10.1016/j.bbacli.2014.05.001

[39] Lang, U.E., Hellweg, R., Bajbouj, M., Gaus, V., Sander, T. and Gallinat, J. (2008) Gender-Dependent Association of a Functional NGF Polymorphism with Anxiety-Related Personality Traits. Pharmacopsychiatry, 41, 196-199. https://doi.org/10.1055/s-0028-1082070

[40] Lu, P., Jones, L.L. and Tuszynski, M.H. (2005) BDNF-Expressing Marrow Stromal Cells Support Extensive Axonal Growth at Sites of Spinal Cord Injury. Experimental Neurology, 191, 344-360. https://doi.org/10.1016/j.expneurol.2004.09.018

[41] Park, H. and Poo, M. (2012) Neurotrophin Regulation of Neural Circuit Development and Function. Nature Reviews Neuroscience, 14, 7-23.

https://doi.org/10.1038/nrn3379

[42] Ropret, S., Zupanc, T., Komel, R. and Videtič Paska, A. (2015) Investigating the Associations between Polymorphisms in the NTRK2 and NGFR Genes and Completed Suicide in the Slovenian Sample. Psychiatric Genetics, 25, 241-248. https://doi.org/10.1097/YPG.0000000000000109 